\title{
High mobility group B1 impairs hepatocyte regeneration in acetaminophen hepatotoxicity
}

\author{
Runkuan Yang ${ }^{1,2^{*}}$, Shutian Zhang ${ }^{3}$, Antonella Cotoia ${ }^{2}$, Niku Oksala ${ }^{4}$, Shengtao Zhu ${ }^{3}$ and Jyrki Tenhunen ${ }^{1,5}$
}

\begin{abstract}
Background: Acetaminophen (APAP) overdose induces massive hepatocyte necrosis. Necrotic tissue releases high mobility group B1 (HMGB1), and HMGB1 contributes to liver injury. Even though blockade of HMGB1 does not protect against APAP-induced acute liver injury (ALI) at $9 \mathrm{~h}$ time point, the later time points are not studied and the role of HMGB1 in APAP overdose is unknown, it is possible that neutralization of HMGB1 might improve hepatocyte regeneration. This study aims to test whether blockade of HMGB1 improves hepatocyte regeneration after APAP overdose.
\end{abstract}

Methods: Male C57BL/6 mice were treated with a single dose of APAP (350 mg/kg). 2 hrs after APAP administration, the APAP challenged mice were randomized to receive treatment with either anti-HMGB1 antibody (400 $\mu \mathrm{g}$ per dose) or non-immune (sham) IgG every 24 hours for a total of 2 doses.

Results: 24 hrs after APAP injection, anti-HMGB1 therapy instead of sham IgG therapy significantly improved hepatocyte regeneration microscopically; 48 hrs after APAP challenge, the sham IgG treated mice showed 14.6\% hepatic necrosis; in contrast, blockade of HMGB1 significantly decreased serum transaminases (ALT and AST), markedly reduced the number of hepatic inflammatory cells infiltration and restored liver structure to nearly normal; this beneficial effect was associated with enhanced hepatic NF-KB DNA binding and increased the expression of cyclin D1, two important factors related to hepatocyte regeneration.

Conclusion: HMGB1 impairs hepatocyte regeneration after APAP overdose; Blockade of HMGB1 enhances liver recovery and may present a novel therapy to treat APAP overdose.

\section{Background}

Acetaminophen hepatotoxicity is the leading cause of druginduced acute liver failure (ALF) in the United States and other industrialized nations [1]. Massive necrosis is the dominant feature of APAP -induced ALI [2-6] and necrotic tissue passively releases HMGB1 [7-9], an important late inflammatory mediator that was well studied in sepsis [10], and HMGB1 contributes to liver injury [11,12]; this indicates that HMGB1 might play an important role in the pathogenesis of APAP hepatotoxicity. Although blockade of HMGB1 in an APAP-induced ALI model does not protect against liver injury at $9 \mathrm{~h}$ point, inflammation is reduced as seen by myeloperoxidase (MPO) activity in total liver

\footnotetext{
* Correspondence: bobyangr@yahoo.com

'Department of Intensive Care Medicine, University of Tampere Medical

School, Tampere 33014, Finland

${ }^{2}$ Department of Critical Care Medicine, University of Pittsburgh Medical

School, 3550 Terrace Street, Pittsburgh PA 15261, USA

Full list of author information is available at the end of the article
}

extract [9], however, the later time points are not studied and the role of HMGB1 in APAP overdose is still not known. It is possible that neutralization of HMGB1 might improve hepatocyte regeneration in APAP toxicity.

Based on these observations, we hypothesized that HMGB1 impairs hepatocyte regeneration after APAP overdose and treated APAP challenged mice with antiHMGB1 neutralizing antibody or non-immune IgG for 24 or 48 hours.

\section{Methods}

Materials

All chemicals were purchased from Sigma-Aldrich Chemical Co. (St. Louis, MO, USA) unless otherwise noted. Polyclonal antibodies against HMGB1 were raised in rabbits (Cocalico Biologicals, Reamstown, PA, USA), and titers were determined by immunoblotting as previously described [13]. Anti-HMGB1 antibodies were affinitypurified by using cyanogen bromide-activated Sepharose

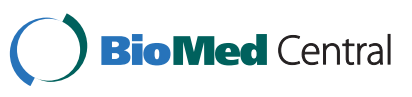


beads following standard procedures. Neutralizing activity of anti-HMGB1 was confirmed in HMGB1-stimulated macrophage cultures by assay of TNF- $\alpha$ release. In the presence of anti-HMGB1 antibody, neutralizing antibody was defined as inhibiting $>80 \%$ of HMGB1-induced TNF release. Sham IgG antibodies were purified from nonimmunized rabbit IgG.

\section{Ethical considerations}

This research protocol complied with the regulations regarding the care and use of experimental animals published by the National Institutes of Health and was approved by the Institutional Animal Use and Care Committee of the University of Tampere Medical School. Male C57BL/6 mice weighing 20-25 g (University of Kuopio animal care center, Kuopio, Finland) were used in this study. The animals were maintained at the University of Kuopio Animal Research Center with a 12hour light-dark cycle and free access to standard laboratory food and water. The animals were fasted over night prior to the experiments.

\section{Animal experiments}

In the first experiment, 10 mice were randomized into the APAP group and the control group $(n=5$ for each group). 5 mice in the APAP group were i.p. injected with a single sub lethal dose of APAP (300 $\mathrm{mg} / \mathrm{kg}$ dissolved in $1 \mathrm{~mL}$ sterile saline) and 5 mice in the control group were injected with same volume of saline not containing APAP. 24 hrs after APAP injection, the animals in each group were anesthetized with sodium pentobarbital (90 $\mathrm{mg} / \mathrm{kg}$ i.p.) and blood was aspirated from the heart to measure serum HMGB1 by western blot.

In the second experiment, ALI was induced by a single dose of APAP (350 mg/kg dissolved in $1 \mathrm{~mL}$ sterile saline) administered by i.p. injection. 14 APAP challenged mice were then randomized into the anti-HMGB1 group $(n=6)$ and the sham IgG group $(\mathrm{n}=8) .6$ mice injected with saline not containing APAP served as the control group. The animals in the anti-HMGB1 group were given 1 dose of anti-HMGB1 antibody (400 $\mu \mathrm{g}$ per dose dissolved in $0.5 \mathrm{~mL}$ sterile saline) $2 \mathrm{hrs}$ after APAP injection. The same amount of sham IgG and saline were given to the sham IgG group or the control group at equivalent time points. 24 hrs after APAP injection, all surviving mice in each group were anesthetized with sodium pentobarbital (90 mg/kg i.p.), serum was collected to measure ALT, AST and HMGB1 and the left lobe of the liver was stored in $10 \%$ formalin for pathology (HE staining).

In the third experiment, ALI was induced the same as above described. APAP injected mice were then randomized into the anti-HMGB1 group $(\mathrm{n}=10)$ and the sham IgG group $(\mathrm{n}=11) .6$ mice injected with saline not containing APAP served as the control group. The animals in the anti-HMGB1 group were given 2 doses of antiHMGB1 antibody ( $400 \mu \mathrm{g}$ per dose dissolved in $0.5 \mathrm{~mL}$ sterile saline): the first dose was given 2 hrs after APAP injection, the second dose were given 24 hrs after the first dose of anti-HMGB1 antibody.

The same amount of sham IgG and saline were given to the sham IgG group or the control group at equivalent time points. $48 \mathrm{hrs}$ after APAP injection, all surviving mice in each group were anesthetized with sodium pentobarbital $(90 \mathrm{mg} / \mathrm{kg}$ i.p.), and the following procedures were performed: 1) blood was aspirated from the heart to measure serum ALT and AST; 2) the left lobe of the liver was stored in $10 \%$ formalin for pathology (HE staining); 3 ) the rest of the liver tissue was harvested and frozen for subsequent protein extractions.

In the fourth experiment, 3 separate groups of mice were used. ALI was induced the same as above described. The treatments remained the same as described in the second experiment except one more dose of anti-HMGB1 or sham IgG was given $48 \mathrm{~h}$ after the first dose and animals were sacrificed at $72 \mathrm{~h}$ time point. Except relatively smaller necrosis (8\%) in the sham IgG group at 72 time point, the other parameters such as NF-kB and cyclin D1 at $72 \mathrm{~h}$ were comparable to the $48 \mathrm{~h}$ time point, therefore, this study focused on $24 \mathrm{~h}$ and $48 \mathrm{~h}$ time points.

\section{Serum HMGB1 measurements}

HMGB1 levels were measured by western immunoblotting analysis as described [7]. In brief, serum samples $(100 \mu \mathrm{L})$ were ultrafiltered with Centricon 100 (Millpore). The elute was fractionated by SDS/PAGE, transferred to nylon membranes (Bio-Rad), and probed with purified IgG from antiHMGB1 antiserum $(5 \mu \mathrm{g} / \mathrm{ml})$ for western blot analysis. Polyclonal anti-HMGB1 IgG was purified by using protein A agarose according to the manufacturer's instructions (Pierce). Membranes were visualized with an Enhanced Chemiluminescence substrate (ECL, Amersham Pharmacia Biotech) and exposed to X-ray film according to the manufacturer's instructions.

\section{Serum aminotransferase measurements}

Serum levels of AST and ALT were measured at $37^{\circ} \mathrm{C}$ with a commercially available kit (Sigma Diagnostic).

\section{Myeloperoxidase assay for hepatic neutrophils infiltration}

Neutrophils infiltration was measured at 48 hours by determining MPO activity in liver tissue homogenates as previously described [14] and was used as an index of neutrophils infiltration in all groups. The MPO levels were expressed as units per gram of tissue $(\mathrm{U} / \mathrm{g})$.

\section{Light histology studies}

Formalin-fixed hepatic tissue was sectioned, stained with hematoxylin and eosin (H\&E) and examined using light 
microscopy. Blind analysis was performed on all samples to determine the degree of lesion as previously described [15]. The percentage of necrosis was estimated by evaluating the number of microscopic fields with necrosis compared with the entire cross section. Inflammatory cell infiltration results were scored semi-quantitatively by averaging the number of inflammatory cells per microscopic field at a magnification of $200 \times$. Five fields were evaluated per tissue sample; six animals in each group were examined at $24 \mathrm{~h}$ time point; six animals in the control group, nine animals in the sham IgG group and 10 animals in the anti-HMGB1 group were examined at $48 \mathrm{~h}$.

\section{Western blot for cyclin D1 measurement}

Liver protein was extracted as previously described [13]. Equivalent amounts of protein were boiled in sample buffer and subjected to $7.5 \%$ precast SDS-polyacrylamide gels (Bio-Rad) and transferred to nylon membranes. Membranes were then probed with a specific antibody against cyclin D1 (Cell signaling Technology, Lexington, KY) protein, visualized with an Enhanced Chemiluminescence substrate (ECL, Amersham Pharmacia Biotech) and exposed to X-ray film according to the manufacturer's instructions.

\section{Assessment of NF-KB activation}

$\mathrm{NF}-\mathrm{kB}$ activation was determined by EMSA, as previously described [16]. The gels were dried and exposed to Biomax film (Kodak, Rochester, NY) at $-70^{\circ} \mathrm{C}$ overnight with use of an intensifying screen.

\section{Hepatocyte proliferation (DNA synthesis)}

Since at $24 \mathrm{~h}$ time point, the APAP challenged C57/BL6 mice only showed occasional hepatocyte nuclei labeled for 5-bromo-2-deoxyuridine (BrdU) [17], therefore, BrdU test was performed only at $48 \mathrm{~h}$ time point in this study. To evaluate hepatocyte regeneration, mice from the $48 \mathrm{~h}$ groups were administered BrdU (50-mg/ kg i.p. injection at $46 \mathrm{~h}$ time point) 2 hours before they were killed. Parraffin-embedded liver sections were prepared and processed for immunohistochemistry using BrdU in-situ staining kits from BD Pharmingen (San Jose, CA, USA) according to the manufacturer's instructions. Digital images of 5 low-power fields from each liver were obtained in a random and blinded fashion, and the number of BrdU-labeled hepatocyte nuclei was counted. The average number of BrdU-positive hepatocytes in each animal was used for subsequent analysis.

\section{Statistics}

Data are presented as means \pm SEM. Continuous data were analyzed using student's t-test or analysis of variance followed by Fisher's LSD test. Probability levels less than 0.05 were considered significant $(\mathrm{p}<0.05)$.

\section{Results}

24 h time point serum HMGB1

Western blot was performed to measure serum HMGB1 from the normal control and the APAP groups $(n=5$ animals for each group, each band stands for one serum sample from the control or APAP groups). 24 hrs after APAP injection, the serum HMGB1 level in APAP challenged mice was significantly higher than that in the control group (Figure 1).

\section{Serum ALT and AST at $24 \mathrm{~h}$ and $48 \mathrm{~h}$ time points}

$24 \mathrm{hrs}$ after APAP injection, 2 mice from sham IgG group died, all mice in the anti-HMGB1 group and the control group survived. Anti-HMGB1 therapy did not statistically decrease serum ALT/AST than that in the sham IgG group ( $n=6$ for each group). 48 hrs after APAP challenge, the survival rate was $81.8 \%(9 / 11)$ in the sham IgG group and $100 \%(10 / 10)$ in the anti-HMGB1 therapy group; all mice survived in the control group. Repeatedly, serum ALT/ AST decreased rapidly at $48 \mathrm{~h}$ time point as compared to $24 \mathrm{~h}$ time point. Compared to sham IgG treatment, blockade of HMGB1 significantly reduced serum concentrations

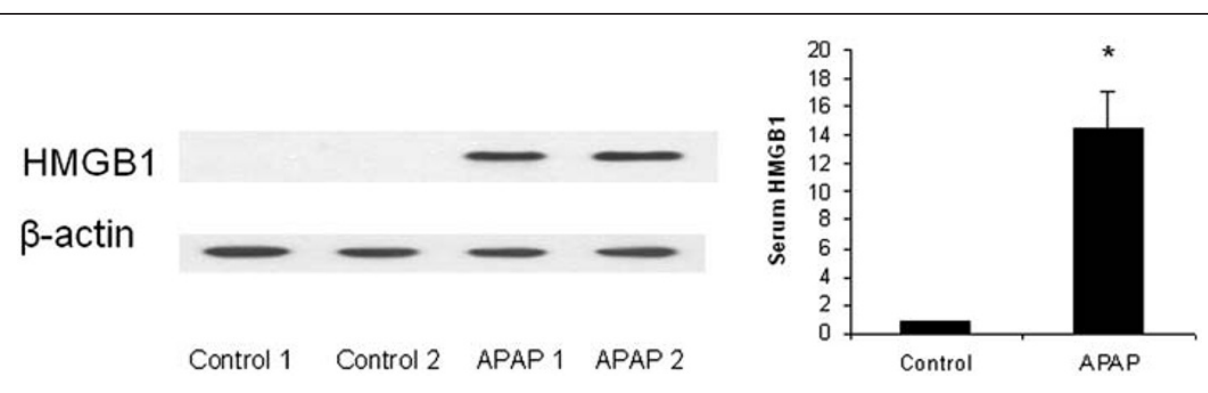

Figure 1 Serum HMGB1 in APAP-induced ALI model. ALI was induced in C57BI/6 male mice with a single dose of APAP by intraperitoneal (i.p.) injection (300 mg/kg dissolved in $1 \mathrm{~mL}$ saline), each control animal was injected with $1 \mathrm{~mL}$ saline not containing APAP ( $n=5$ animals for each group). Western blot was performed by using serum obtained 24 hours after APAP injection. Results from 5 representative assays are shown $(n=5$, each band stands for one serum sample from the control or APAP injected animals). Typical gels are depicted. 
of ALT and AST at $48 \mathrm{~h}$ time point (tindicates $\mathrm{p}<0.05 \mathrm{vs}$. sham IgG) (Figure 2)

\section{Histopathology}

24 hrs after APAP injection, microscopically, the most conspicuous feature was the evident hepatocyte regeneration in the anti-HMGB1 therapy group compared with sham IgG treated mice. In histological evaluation $48 \mathrm{hrs}$ after ALI induction, compared to control animals, sham IgG treated mice demonstrated $14.6 \pm 1.2 \%$ necrotic area and extensive infiltration of inflammatory cells $(270 \pm 40$ per high power field, $n=9$ ) in the centrilobular regions. Loss of cell boundaries and ballooning degeneration were also found around hepatic central vein in the sham IgG group. In contrast, anti-HMGB1 therapy significantly reduced the number of inflammatory cells $(100 \pm 35$ per high power field, $\mathrm{n}=10)$ and demonstrated $1.6 \pm 0.3 \%$ necrosis around the central vein, the necrosis was not yet completely replaced by regeneration, even though the liver structure has restored to nearly normal (Figure 3 ).

\section{Liver tissue MPO level}

At $48 \mathrm{~h}$ time point, the mean liver MPO activity value for the control group $(n=6)$ was $4.2 \pm 0.29 \mathrm{U} / \mathrm{g}$, this value increased to $5.64 \pm 0.40 \mathrm{U} / \mathrm{g}$ in the sham IgG group $(\mathrm{n}=9)$ and $4.90 \pm 0.40 \mathrm{U} / \mathrm{g}$ in the anti-HMGB1 group $(\mathrm{n}=10)$, no statistical difference between the sham IgG and antiHMGB1 groups $(\mathrm{p}=0.073$, data were shown as Mean \pm SEM).

\section{Hepatic NF-KB DNA binding}

NF- $\mathrm{kB}$ is a pleiotropic transcription factor whose activation has been linked to inflammatory and destructive processes, as well as initiation of regenerative programs in the injured liver. Blockade of HMGB1 protects against ischemia-reperfusion (I/R)-induced liver injury; this protection is associated with increased NF- $\mathrm{kB}$ DNA binding activity [12]. Therefore, we examined the impact of APAP on activation of NF- $\mathrm{kB}$ at 48 hours after APAP injection and tested the effect of HMGB1 blockade. There was a low basal level of NF- $\kappa B$ DNA binding in the hepatic tissue samples in the control group. In the sham IgG group, there was a marked increase in NF- $\mathrm{kB}$ DNA binding. Treatment of mice after APAP challenge with antiHMGB1 neutralizing antibody clearly increased NF- $\mathrm{kB}$ DNA binding relative to the degree observed in mice treated with non-immune IgG (Figure 4). NF-kB DNA binding was not consistent at $24 \mathrm{~h}$ time point.
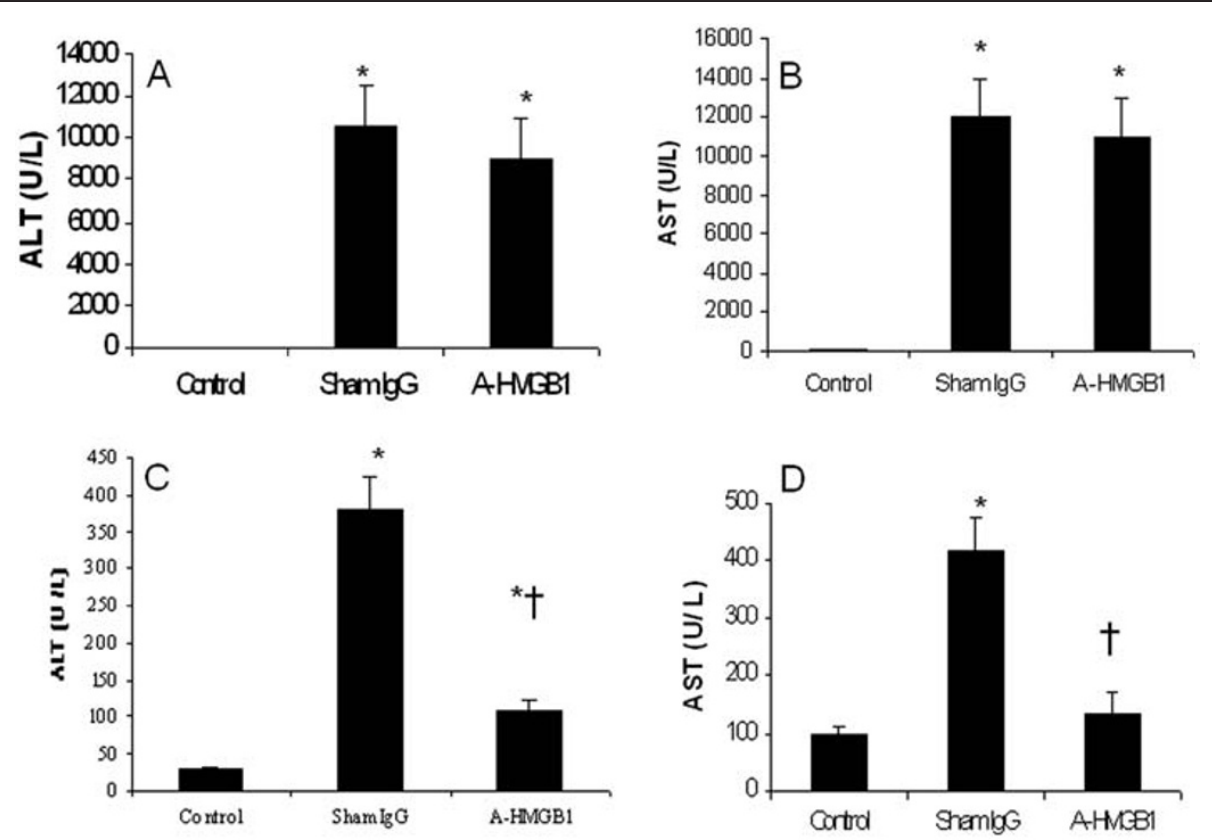

Figure 2 Effect of treatment with anti-HMGB1 antibody or sham IgG on serum ALT/AST in acetaminophen (APAP)-induced acute liver injury (ALI). ALI was induced in C57 BL/6 male mice with a single dose of APAP (350 mg/kg) by i.p. injection. 2 hours after APAP administration, the first dose of $400 \mu \mathrm{g}$ of anti-HMGB1 antibody in $0.5 \mathrm{~mL}$ saline was i.p. injected into mice in the anti-HMGB1 group, the same amount of sham IgG or saline solution was given to the sham lgG and the control animals at the equivalent time points. The same dose was repeated 24 hrs after the first dose. Figure 2A, 2B: Serum ALT/AST was assessed 24 hrs after APAP injection from the anti-HMGB1 group, the sham IgG and the control group ( $n=6$ for each group). Figure 2C and 2D: 3 separate groups of mice were used. Serum ALT and AST were assessed at $48 \mathrm{~h}$ time point from the anti-HMGB1 group $(n=10)$, the sham IgG group $(n=9)$ and the control group $(n=6)$. Results are means \pm SEM. * indicates $p<0.05$ vs. control; $†$ indicates $p<0.05$ vs. sham lgG. 

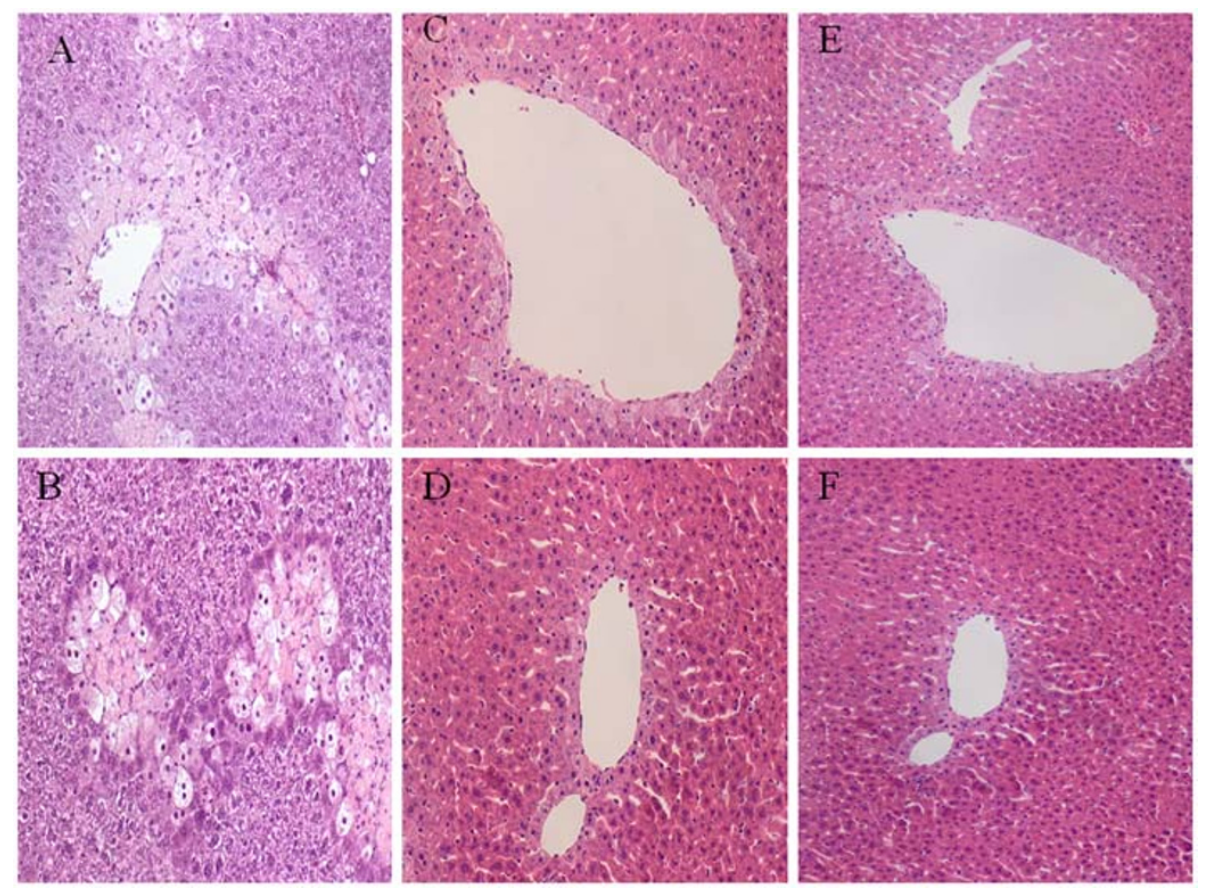

Figure 3 Effect of treatment with anti-HMGB1 antibody or sham IgG on pathology in mice with ALI. Hematoxylin-eosin staining was assessed 24 and $48 \mathrm{~h}$ after induction of ALI (or sham procedure). Method and treatment were the same as described in Figure 2 ( $n=6$ for each group at $24 \mathrm{~h}$ time point; at $48 \mathrm{~h}$ time point, $\mathrm{n}=9$ for the sham IgG group, $\mathrm{n}=10$ for the anti-HMGB1 group and $\mathrm{n}=6$ for the control group). Typical picture is shown. [A=sham IgG at $24 \mathrm{~h}$ (200x), B=anti-HMGB1 at $24 \mathrm{~h}$ (200x), C=sham IgG at $48 \mathrm{~h}$ (200x), D=anti-HMGB1 at $48 \mathrm{~h}$ (200x), $\mathrm{E}=$ sham lgG at $48 \mathrm{~h}(100 \mathrm{x}), \mathrm{F}=$ anti-HMGB1 at $48 \mathrm{~h}(100 \mathrm{x})]$.

\section{Hepatic cyclin D1 expression}

The induction of cyclin D1 is the most reliable marker for cell cycle (G1 phase) progression in hepatocytes [18] Western blot was performed using whole-cell extracts prepared from liver tissue to assess expression of cyclin D1 in mice subjected to ALI or the control procedure. In Figure 5, cyclin D1 expression in the control group and sham IgG group was undetectable or minimal. In contrast, cyclin D1 expression was clearly observed in anti-HMGB1 antibody-treated animals at $48 \mathrm{~h}$ after APAP administration.

Cyclin D1 expression in the sham and anti-HMGB1 groups was the same level as in the control group that was almost undetectable at $24 \mathrm{~h}$ time point.

\section{Hepatic BrdU expression}

The hepatocyte proliferation was assessed by BrdU immunohistological staining. BrdU-positive nuclei were shown by the arrows. At 48 hours, the number of labeled nuclei (per low power) was significantly increased in both sham IgG $(71 \pm 8)$ (Figure 6B) and anti-HMGB1 $(16 \pm 4)$ (Figure 6C) groups, although to a statistically lesser extent in the anti-HMGB1 treated mice; after $48 \mathrm{~h}$, the extent of hepatic BrdU expression, however, depended mainly on the extent of damage, because it was significantly correlated with the area of hepatocyte necrosis for each mouse [17]; our result showed that the sham IgG group had larger necrotic area $(14.6 \pm 1.2 \%)$ than the anti-HMGB1 group $(1.6 \pm 0.3 \%)$, resultantly, the sham IgG group had a larger number of BrdU-positive cells than the anti-HMGB1 group, our result was consistent with Javier Vaquero's report [17].

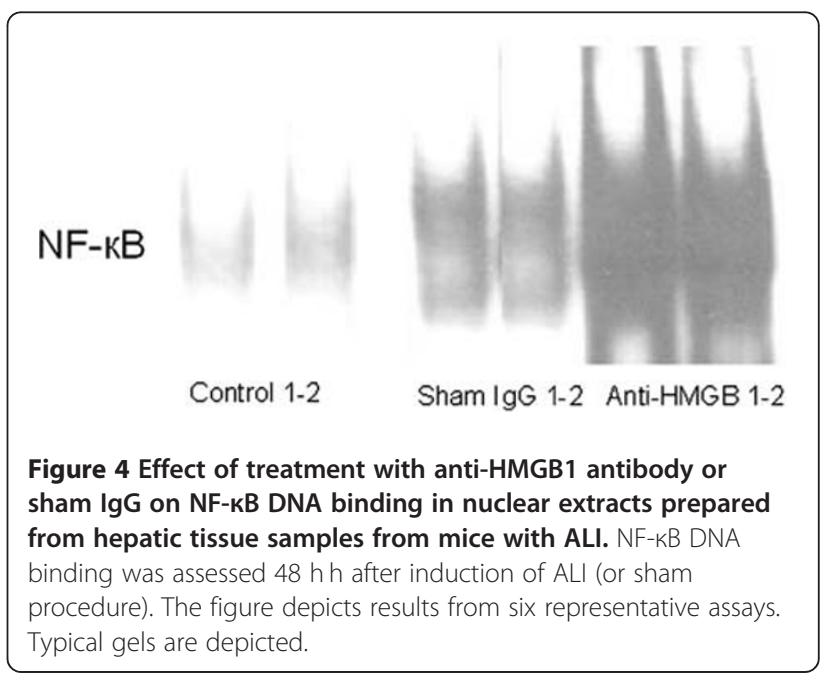




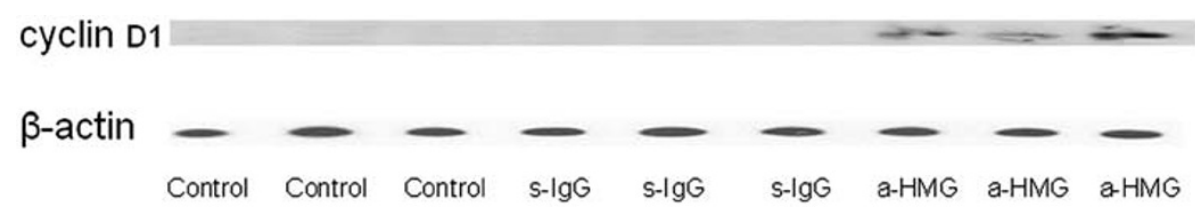

Figure 5 Effect of treatment with anti-HMGB1 or sham IgG on the expression of cyclin D1 in the hepatic tissue. Western blot was performed using hepatic extracts prepared from tissues obtained $48 \mathrm{hrs}$ after APAP injection. The figure depicts results from six representative assays. Typical gels are depicted.

\section{Discussion}

HMGB1 is a well-known and studied protein, which is very conservative among species and acts as a nuclear protein that promotes transcriptional activation. It acts late in the time line as a downstream inflammatory mediator in sepsis [10]. HMGB1 also is released readily from necrotic or damaged cells, and serves as a signal for inflammation [19]. The purpose of this study was to test the notion that HMGB1 impairs hepatocyte regeneration after APAP overdose. The major and the novel findings of this investigation are: (a) serum HMGB1 is increased after APAP challenge and anti-HMGB1 therapy improves hepatocyte regeneration seen in pathology 24 hours after APAP administration; (b) blockade of HMGB1 decreases serum ALT /AST and enhances liver recovery at $48 \mathrm{~h}$ time point (c) the late phase improvement is associated with an augmented NF-kB DNA binding (d) blockade of HMGB1 significantly increases the expression of cell cycle protein cyclin D1 in liver tissue at $48 \mathrm{~h}$ time point.

In this study, the ALT/AST concentrations were very high at $24 \mathrm{~h}$ time point, however, those surviving mice with high ALT/AST levels did not look severely ill, most of them looked only mildly distressed. In a pilot experiment with a lower dose of APAP $(250 \mathrm{mg} / \mathrm{kg}$ ) administration, the ALT level could rapidly decrease to about $100 \mathrm{u} /$ $\mathrm{L}$ at $48 \mathrm{~h}$, however, the pathology at $48 \mathrm{~h}$ looked much worse than the liver injuries with similar ALT/AST levels caused by hemorrhagic shock and sepsis, therefore, we think ALT/AST concentrations alone can not accurately predict the severity of APAP hepatotoxicity.

In this study, ELISA was also performed to measure 24 h serum HMGB1 level by using HMGB1 ELISA kits from Shino-Test (Kanagawa, Japan). The serum HMGB1 concentrations were $2 \pm 0.2 \mathrm{ng} / \mathrm{mL}$ in the normal control group and $23 \pm 1.4 \mathrm{ng} / \mathrm{mL}$ in APAP injected animals $(\mathrm{n}=5$ for each group, data presented as mean \pm SEM), however, our results in the APAP group were 12 times lower than Antoine DJ' report [20] who used HMGB1 neutralizing antibody from Shino-Test Corporation (Tokyo, Japan), this big difference between the two reports is probably due to the unconvincing HMGB1 ELISA kits, because the manufacturer requires that the serum should be incubated for 24 hours at $37^{\circ} \mathrm{C}$, this key step is unusual and rationally unconvincing, this might make the HMGB1 ELISA procedure unreliable and Shino-Test HMGB1 ELISA kits (Kanagawa, Japan) is currently the only available commercial HMGB1 ELISA kits; in contrast, HMGB1 western blot is the conventional method and is still commonly used, currently the HMGB1 western blot is probably more reliable than HMGB1 ELISA procedure, therefore, HMGB1 western blot is shown in this study.

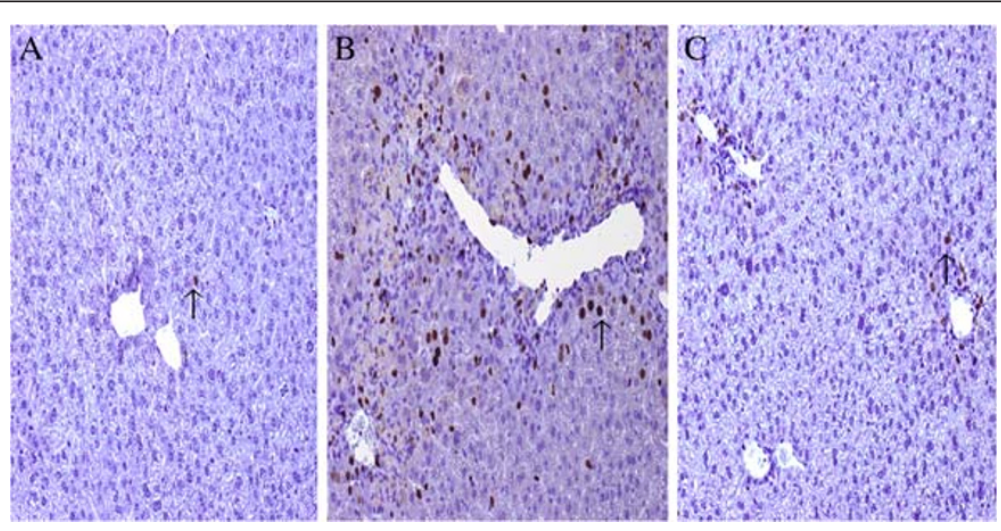

Figure 6 Effect of treatment with sham or anti-HMGB1 antibodies on hepatocyte regeneration in acetaminophen (APAP)-injected mice. 5-bromo-2-deoxyuridine (BrdU) staining was assessed at 48 hours after induction of acute liver injury (ALI) (or sham procedure, $\mathrm{n}=6$ for each group). A typical picture is shown. BrdU-positive nuclei are indicated by arrows. ( $\mathrm{A}=48 \mathrm{~h}$ Control, $\mathrm{B}=48 \mathrm{~h} \mathrm{Sham} \mathrm{IgG,} \mathrm{C=48} \mathrm{h} \mathrm{anti-HMGB1).}$ 
Antoine DJ et al [20] showed that blockade of HMGB1 significantly decreased serum ALT/AST and injury score at $24 \mathrm{~h}$ time point, this is different from our $24 \mathrm{~h}$ results in which neutralization of HMGB1 did not significantly decrease serum ALT/AST but enhanced hepatocyte regeneration in HE staining, our $24 \mathrm{~h}$ results suggest that HMGB1 probably is not an important early injurious factor in this model, this notion is further supported by our previous study [11] in which a high dose of exogenous HMGB1 injection increased ALT level to $350 \mathrm{u} / \mathrm{L}$ in normal mice at $18 \mathrm{~h}$ time point; in contrast, APAP overdose could increase ALT level to $4000-10000 \mathrm{u} / \mathrm{L}$ at $24 \mathrm{~h}$ in mice. Blockade of HMGB1 from two different research groups had different results at $24 \mathrm{~h}$ time point, suggest that the role of HMGB1 in this model is still controversial and more investigation is needed. The different $24 \mathrm{~h}$ results from two different research groups are probably caused by different antibody sensitivity and specificity. Our study also showed that HMGB1 was involved in liver regeneration, in which the later time point is important, however, the later time point or underlying mechanisms were not studied in Antoine DJ's report [20].

To elucidate the molecular basis of liver recovery in blocking of HMGB1, we investigated its effect on NF-kB signaling pathway because currently, NF- $\mathrm{KB}$ is thought to play a major role in the initiation of liver regeneration after cell or tissue loss (such as partial hepatectomy) [18,21], and enhanced NF-kB DNA binding is associated with better liver recovery in APAP hepatotoxicity [22]. Our data suggested that blockade of HMGB1 is associated with a beneficial response characterized by activation of NF- $\mathrm{kB}$. Although NF- $\mathrm{kB}$ activation modulates inflammation [10], it is also known to protect hepatocytes from cell death, and inhibition of NF-kB after partial hepatectomy results in massive hepatocyte apoptosis, worsens liver injury and decreases survival [23]. There is evidence suggesting that the impact of APAP toxicity ensues, at least in part, by dramatic modulation of inflammatory and/ or regeneration programs [24]. It is possible that in HMGB1-blocked mice subjected to APAP overdose, enhanced NF- $\mathrm{KB}$ activation diverts intracellular pathways from those associated with inflammation and cell death, to mechanisms linked to recruitment and activation of pro-regenerative programs, therefore, activation of NF-kB by blockade of HMGB1 might facilitate regeneration in this ALI induced by APAP.

Liver regeneration is a vital process for survival after a toxic insult [25-27]. Regeneration ensures the replacement of necrotic cells and the full recovery of organ function. The exposure to growth factor such as hepatocyte growth factor results in the expression of cell cycle proteins [18]. The induction of cyclin D1 is the most reliable marker for cell cycle $\left(G_{1}\right.$ phase) progression in hepatocytes [18]. Once hepatocytes express cyclin D1, they have passed the $G_{1}$ restriction point and are committed to DNA replication [18].
In current investigation, our western blot data showed that neutralization of HMGB1 markedly increased the level of cyclin D1 in the APAP challenged liver tissue. These changes in cyclin D1 expression were associated with decreased serum ALT /AST and improved liver regeneration in anti-HMGB1 antibody -treated mice receiving APAP, suggesting that blockade of HMGB1 likely facilitates activation of cyclin D1-mediated regeneration pathways, and the increased cyclin D1 expression might be modulated by enhanced NF- $\kappa B$ DNA binding [18]. Our data suggest that HMGB1 is an important factor, which impairs hepatocyte regeneration in APAP overdose. Anti-HMGB1 antibody treatment lowered serum ALT/AST at $48 \mathrm{~h}$ time point, probably by blocking HMGB1 to reduce inflammation and to improve hepatocyte regeneration, resultantly hastened liver recovery from APAP hepatotoxicity.

Currently $\mathrm{N}$-acetyl-cysteine (NAC), a glutathione precursor, is the antidote for APAP overdose [28]. However, this antidotal therapy is effective only for patients who present within hours of an acute overdose, and is less effective for late-presenting patients [28,29]. In addition, prolonged treatment with NAC delays liver recovery from APAP hepatotoxicity [30]. Up to date treating delayed cases with APAP overdose is still problematic, additional therapies are needed. Treatment with antiHMGB1 neutralizing antibody would serve as an adjuvant to NAC therapy. Further experiments designed to compare the two therapies are needed in the future.

\section{Conclusion}

HMGB1 impairs hepatocyte regeneration after APAP overdose; blockade of HMGB1 enhances liver recovery and may present a novel therapy to treat APAP overdose.

\section{Competing interests}

The authors declare that they have no competing interests.

\section{Authors' contributions}

RKY designed the study. All authors participated in the animal handling and procedures. All authors read and approved the final manuscript.

\section{Acknowledgements}

This study was partly supported by Sigrid Juselius Funding in Finland.

\section{Author details}

'Department of Intensive Care Medicine, University of Tampere Medical School, Tampere 33014, Finland. ${ }^{2}$ Department of Critical Care Medicine, University of Pittsburgh Medical School, 3550 Terrace Street, Pittsburgh PA 15261, USA. ${ }^{3}$ Department of Gastroenterology, Friendship Hospital, Capital Medical School, Beijing China. ${ }^{4}$ Center of Laboratory Medicine, Tampere University Hospital and Surgery, University of Tampere Medical School, Tampere 33014, Finland. ${ }^{5}$ Department of Surgical Sciences/Anaesthesiology and Intensive Care, University of Uppsala Medical School, Uppsala 75185, Sweden.

Received: 17 November 2011 Accepted: 8 May 2012 Published: 8 May 2012

\section{References}

1. Lee WM: Acetaminophen and the U.S. Acute liver failure study group: lowering the risks of hepatic failure. Hepatology 2004, 40:6-9. 
2. Nelson SD: Molecular mechanisms of the hepatotoxicity caused by acetaminophen. Semin Liver Dis 1990, 10:267-278.

3. Cohen SD, Khairallah EA: Selective protein arylation and acetaminophen-induced hepatotoxicity. Drug Metab Rev 1997, 29:59-77.

4. Cressman DE, Greenbaum LE, DeAngelis RA, et al: Liver failure and defective Hepatocyte regeneration in interleukin-6 deficient mice. Science 1996, 274:1379-1383.

5. Jaeschke $H$, Bajt ML: Intracellular signaling mechanisms of acetaminophen-induced liver cell death. Toxicol Sci 2006, 89:31-41.

6. Yamada Y, Kirillova I, Peschon JJ, Fausto N: Initiation of liver growth by tumor necrosis factor: deficient liver regeneration in mice lacking type 1 tumor necrosis factor receptor. Proc Natl Acad Sci 1997, 94:1441-1446.

7. Wang H, Li W, Goldstein R, Tracey KJ, Sama AE: HMGB1 as a potential therapeutic target. Novartis Found Symp 2007, 280:73-85.

8. Yang H, Wang H, Czura CJ, Tracey KJ: The cytokine activity of HMGB1. J Leukocyte Biology 2005, 78:1-8.

9. Scaffidi P, Misteli T, Bianchi ME: Release of chromatin protein HMGB1 by necrotic cells triggers inflammation. Nature 2002, 418:191-195.

10. Ulloa L, Ochani M, Yang H, Tanovic M, Halperin D, Yang R, Czura CJ, Fink MP, Tracey KJ: Ethyl pyruvate prevents lethality in mice with established lethal sepsis and systemic inflammation. Proc Natl Acad Sci 2002, 99:12351-12356.

11. Sappington PL, Yang R, Yang H, Tracey KJ, Deluder RL, Fink MP: HMGB1 B box increases the permeability of Caco-2 enterocytic monolayers and impairs intestinal barrier function in mice. Gastroenterology 2002, 123:790-802.

12. Tsung A, Sahai R, Tanaka H, Nakao A, Fink MP, Lotze MT, Yang H, Li J, Tracey KJ, Geller DA, Billiar TR: The nuclear factor HMGB1 mediates hepatic injury after murine liver ischemia-reperfusion. JEM 2005, 201:1135-1143.

13. Yang R, Harada T, Mollen KP, Prince JM, Levy RM, Englert JA, Galloitsch-Peerta M, Yang L, Yang H, Tracey KJ, Harbrecht BG, Billiar TR, Fink MP: Anti- HMGB1 neutralizing antibody ameliorates gut barrier dysfunction and improves survival after hemorrhagic shock. Mol Med 2006, 12:105-114.

14. Martinez-Mier G, Toledo-Pereyra LH, McDuffie E, Warner RL, Ward PA: $\mathrm{L}$-selectin and chemokine response after liver ischemia and reperfusion. JSR 2000, 93:156-162.

15. Su GL, Gong KQ, Fan MH, Kelley WM, Hsieh J, Sun JM, Hemmila MR, Arbabi S, Remick DG, Wang SC: Lipopolysaccharide-binding protein modulates acetaminophen-induced liver injury in mice. Hepatology 2005, 41:187-195.

16. Yang R, Gallo DJ, Baust JJ, Uchiyama T, Watkins SK, Delude RL, Fink MP: Ethyl pyruvate modulates inflammatory gene expression in mice subjected to hemorrhagic shock. Am J Physiol Gastrointest Liver Physiol 2002, 283:G212-G222.

17. Vaquero J, Belanger $M$, James $L$, et al: Mild hypothermia attenuates liver injury and improves survival in mice with acetaminophen toxicity. Gastroenterology 2007, 132:372-408.

18. Fausto N: Liver regeneration. J Hepatology 2000, 32:19-31.

19. Bianchi ME, Manfredi AA: High mobility group B1 (HMGB1) protein the crossroads between innate and adaptive immunity. Immunol Rev 2007, 220:35-46.

20. Antoine DJ, Williams DP, Kipar A, Laverty H, Park BK: Diet restriction inhibits apoptosis and HMGB1 oxidation and promotes inflammatory cell recruitment during acetaminophen hepatotoxicity. Mol Med 2010, 16:479-490.

21. Cataldegirmen G, Zeng S, Feirt N, Ippagunta N, Dun H, Qu W, Lu Y, Rong L, Hofmann MA MA, Kislinger T, Pachydaki SI, Jenkins DG, Weinberg A, Lefkowitch J, Rogiers X, Yan S, Schmidt AM, Emond JC: Rage limits regeneration after massive liver injury by coordinated suppression of TNF- $\alpha$ and NF-kB. JEM 2005, 201:473-484

22. Yang R, Zhang S, Kajander H, Zhu S, Koskinen ML, Tenhunen J: Ringer's lactate improves liver recovery in a murine model of acetaminophen toxicity. BMC Gastroenterol 2011, 11:125

23. limuro Y, Nishiura T, Hellerbrand C, Behrns KE, Schoonhoven R, Grishma JW, Brenner DA: NF kappa B prevents apoptosis and liver dysfunction during liver regeneration. J Clin Invest 1998, 101:802-811.

24. Kaplowitz N: Acetaminophen hepatotoxicity. What do we know, what don't we know, and what do we do next? Hepatology 2004, 40:23-26.

25. Chanda S, Mehendale HM: Hepatic cell division and tissue repair: a key to survival after liver injury. Mol Med Today 1996, 2:82-89.
26. Akerman P, Coto P, Yang SQ, McClain C, Nelson S, Bagby GJ, Diehl AM: Antibodies to tumor necrosis factor-alpha inhibit liver regeneration after partial hepatectomy. Am J Physiol 1992, 263:G579-G585.

27. Mehendale HM: Tissue repair: an important determinant of final outcome of toxicant-induced injury. Toxicol Pathol 2005, 33:41-51.

28. Whyte IM, Francis B, Dawson AH: Safety and efficacy of intravenous $\mathrm{N}$-acetylcystine for acetaminophen overdose: analysis of the Hunter Area Toxicity service (HATS) Database. Curr Med Res Opin 2007, 23:2359-2368.

29. Kerr F, Dawson A, Whyte $\mid H$, Buckley N, Murray L, Graudins A, Chan B, Trudinger B: The austrilian clinical toxicology investigators collaboration Randomized trial of different loading infusion rates of $\mathrm{N}$-acetylcystine. Annals of Emergency Med 2005, 45:402-408.

30. Yang R, Miki K, He X, Killeen EM, Fink MP: Prolonged treatment with $\mathrm{N}$-acetylcysteine delays liver recovery from acetaminophen hepatotoxicity. Crit Care 2009, 13:R55.

doi:10.1186/1471-230X-12-45

Cite this article as: Yang et al.: High mobility group B1 impairs hepatocyte regeneration in acetaminophen hepatotoxicity. BMC Gastroenterology 2012 12:45.

\section{Submit your next manuscript to BioMed Central and take full advantage of:}

- Convenient online submission

- Thorough peer review

- No space constraints or color figure charges

- Immediate publication on acceptance

- Inclusion in PubMed, CAS, Scopus and Google Scholar

- Research which is freely available for redistribution 